\title{
Inchworm-like source evolution through a geometrically complex fault fueled persistent supershear rupture during the 2018 Palu Indonesia earthquake
}

\author{
Ryo Okuwaki*a,c, Shiro Hirano ${ }^{\mathrm{b}}$, Yuji Yagi ${ }^{\mathrm{c}}$, Kousuke Shimizu ${ }^{\mathrm{d}}$ \\ ${ }^{a}$ Mountain Science Center, University of Tsukuba, Tsukuba, Ibaraki 305-8572, Japan \\ ${ }^{b}$ College of Science and Engineering, Ritsumeikan University, Kusatsu, Shiga 525-8577, Japan. \\ ${ }^{c}$ Faculty of Life and Environmental Sciences, University of Tsukuba, Tsukuba, Ibaraki 305-8572, Japan \\ ${ }^{d}$ Graduate School of Life and Environmental Sciences, University of Tsukuba, Tsukuba, Ibaraki 305-8572, Japan
}

\section{Highlights}

- Detailed kinematic source model was constructed for 2018 Palu earthquake

- Slip and fault geometry were simultaneously resolved by teleseismic potency-density inversion

- Transient slip acceleration and deceleration across fault bends sustained supershear rupture

\begin{abstract}
How does fault slip follow an earthquake rupture front propagating faster than the local shear-wave velocity (i.e., at supershear speed)? How does a supershear rupture front pass through a geometrically complex fault system? Resolving the evolution of such complex earthquake ruptures is fundamental to our understanding of earthquake-source physics, but these events have not been well captured by conventional waveform inversions of observational data. We applied a new framework of finite-fault inversion to globally observed teleseismic waveforms and resolved both the spatiotemporal evolution of slip and the fault geometry of the 2018 Palu earthquake (moment magnitude 7.6) in Sulawesi, Indonesia. We show that supershear rupture propagation for this event was sustained by transient slip stagnation and advancement as the rupture front passed through the geometrically complex fault system. This peculiar inchworm-like slip evolution was caused by the rupture front encountering fault bends with favorable and unfavorable orientations for rupture propagation. Our analysis also identified the possible existence of a fault junction beneath Palu Bay connecting an unmapped primary fault in northern Sulawesi with the Palu-Koro fault in the south.
\end{abstract}

Keywords: 2018 Palu earthquake, Kinematic source inversion, Complex fault geometry, Supershear rupture

\footnotetext{
${ }^{*}$ Corresponding author rokuwaki@geol.tsukuba.ac.jp (Ryo Okuwaki)
} 


\section{Introduction}

How earthquake ruptures evolve within geometrically complex fault systems is an intriguing issue in earthquake science. Geometric discontinuities of fault strength or regions of increased fracture energy have been characterized as geometric barriers to rupture propagation (Das and Aki, 1977, Aki, 1979). Theoretical studies have confirmed that such barriers, which include changes of fault roughness, perturb rupture propagation (Das and Aki, 1977, Kase and Day, 2006, Huang, 2018). Seismic-waveform analyses have resolved complex evolution of ruptures associated with geometric barriers and have shown that such barriers can control both rupture direction and speed (Bouchon et al., 2001, Uchide et al., 2013, Okuwaki and Yagi, 2018). However, there is a need for further investigation of the relationship between the geometric complexity of a fault system and irregular high-speed rupture propagation that exceeds the local $S$-wave velocity (known as supershear rupture). Numerical studies have shown that although barriers disturb rupture propagation, the large stress drop as rupture propagates across the barrier can promote supershear rupture (e.g., Dunham et al., 2003). Analyses of observed waveforms, however, have generated diverse views of the relationship of supershear rupture to the geometric complexity of fault systems. For example, Bouchon et al. (2010) reported that supershear rupture is likely promoted along smooth faults, rather than along those that are geometrically complex, and Bao et al. (2019) showed that supershear rupture can persist across major bends in a fault system. Nonetheless, the details of the kinematic evolution of supershear fault rupture across geometrically complex fault systems have not been well resolved from analyses of observational data.

Kinematic information about earthquake rupture can be inferred from kinematic source inversion (e.g., Olson and Apsel, 1982, Hartzell and Heaton, 1983) to resolve the spatiotemporal evolution of slip. This information is essential for understanding how slip follows an earthquake rupture front that is propagating at supershear speed and how the supershear rupture front is affected by geometric complexity, neither of which has yet been well resolved by waveform analyses. Moreover, geometric complexity in a fault system makes reliable estimation of kinematic slip evolution difficult (Shimizu et al., 2020). In conventional finite-fault modeling, model fault planes are usually presumed to be either rectangular or configurations of multiple rectangles and polygons. These models may not adequately represent actual fault geometries and can increase modeling errors, thus preventing the plausible solution and robust interpretation of kinematic source processes (Mai et al., 2016, Ragon et al., 2018, Shimizu et al., 2020). For teleseismic body waves generated by strike-slip earthquakes in particular, radiation patterns are sensitive around nodal shear planes. If such earthquakes occur in geometrically complex fault systems, radiation patterns at particular stations can vary as rupture evolves and will not be reproduced if the model fault geometry deviates from the real one.

A moment magnitude $\left(M_{\mathrm{W}}\right) 7.62018$ Palu earthquake in Sulawesi, Indonesia, satisfies such ill conditions for the finite-fault modeling; that is, strike-slip earthquake evolved along geometrically complex fault system. The southern part of its source region includes part of the Palu-Koro fault zone (Bellier et al., 2001, 2006, Figs. 1 and 2), which is near the triple junction of the Australia, Eurasia (or Sunda), and 


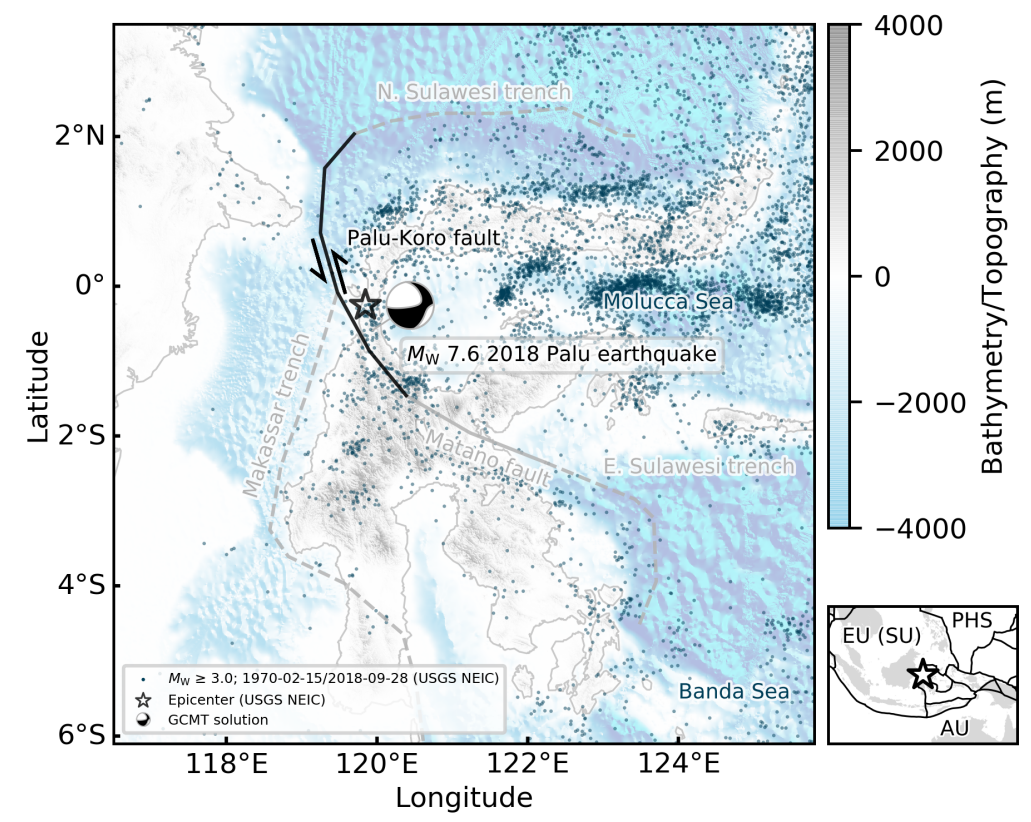

Figure 1: Overview of the study region. The background topography and bathymetry are from the GEBCO 2019 Grid (GEBCO Bathymetric Compilation Group 2019, 2019). The solid lines are the Palu-Koro and Matano faults (Bellier et al., 2006). The dashed lines represent trenches (Bird, 2003). Right-bottom panel is a regional map along with names of major tectonic plates of Australia (AU), Eurasia (EU), Sunda (SU), and Philippine sea (PHS) plates. The black lines represent plate boundaries (Bird, 2003). The star denotes the epicenter.

Philippine sea tectonic plates (Bellier et al., 2001, Socquet et al., 2006). The northern part of the source region, near the epicenter determined by the U.S. Geological Survey National Earthquake Information Center (USGS NEIC), is on a previously unmapped north-trending fault that appears to be off-trend from the main Palu-Koro fault zone (Fig. 2). According to the Global Centroid Moment Tensor (GCMT) solution (GCMT; Dziewonski et al., 1981, Ekström et al., 2012), the 2018 Palu earthquake was the result of left-lateral strike slip, which is consistent with pre-observed Global Positioning System velocity fields (Bellier et al., 2001, Socquet et al., 2006). Interferometric Synthetic Aperture Radar (InSAR) mapping of the surface trace of the active fault during the 2018 earthquake shows bends near the epicenter and south of Palu Bay (Bao et al., 2019, Socquet et al., 2019), thus indicating that the co-seismic shear rupture propagated along a geometrically complex fault system. Based on the spatiotemporal distribution of $P$-wave-radiation sources tracked by the slowness-enhanced back-projection (SEBP; Meng et al., 2016), Bao et al. (2019) showed that the rupture front of the 2018 Palu earthquake propagated south from the epicenter at a sustained supershear speed $\left(4.10 \pm 0.15 \mathrm{~km} / \mathrm{s}\right.$ measured along $174^{\circ}$ strike direction from the epicenter), which was independently confirmed based on the similarity of far-field Rayleigh Mach waves (Dunham and Bhat, 2008, Vallée and Dunham, 2012) from the mainshock of the 2018 Palu earthquake to those of the $M_{\mathrm{W}} 6.1$ foreshock that occurred $30 \mathrm{~km}$ south of the mainshock (Bao et al., 2019). Thus, the 2018 Palu earthquake is a prime candidate for using kinematic source inversion to examine the relationship between the geometric complexity of a fault system and associated supershear rupture propagation. Although the presence of a low-velocity damaged fault zone in the areas near the epicenter and around Palu Bay may have been responsible for unstable rupture propagation including a supershear 


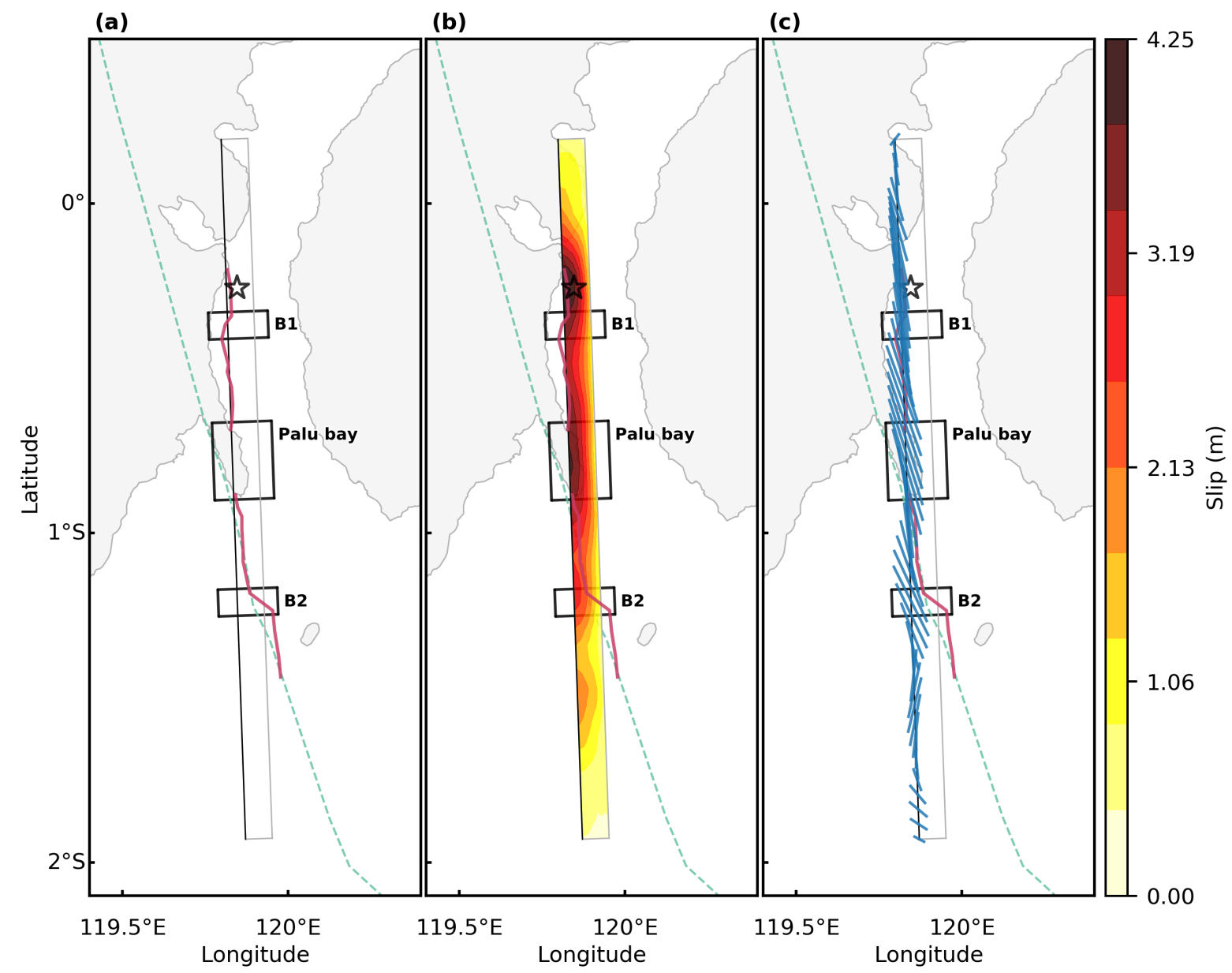

Figure 2: Result in map view. (a) Dashed line is the Palu-Koro fault (Bellier et al., 2001). Red lines are the surface rupture trace mapped by the InSAR analyses (Bao et al., 2019). Black rectangles shows the location of bends and Palu Bay. Gray rectangle outlines a model-fault plane and the black line is a top of the model plane. The star denotes the epicenter. (b) Color contours show the co-seismic slip resolved in this study. (c) Strike orientation extracted from the double-couple components of the resultant potency-density tensors. Only the strike distribution at the top of the model fault is shown for visual simplicity. The full set of strike distribution is shown in Fig. 3b. 
rupture transition (Bao et al., 2019, Oral et al., 2020), the geometric complexity of the fault system might have been also an important control on the kinematics of the evolution of supershear rupture.

We used finite-fault inversion of globally observed teleseismic data to examine the effects of along-strike variations of fault geometry on rupture propagation and slip evolution during the 2018 Palu earthquake. We represented slip by five-basis double-couple components of potency-density tensor (Shimizu et al., 2020), which enabled us to represent slip along a plane that is independent from the presumed modelplane geometry. We took into account the possibility of supershear rupture by resolving slip in a wide parametric model space with a slip-rate function duration long enough and maximum rupture velocity fast enough to allow flexibility in building a slip model. Stagnation of slip behind unfavorably oriented fault bends and transient slip advancement through fault bends should provide critical observational evidence of the persistent, but transiently propagating, supershear rupture across the geometrically complex strikeslip fault.

\section{Method}

Resolving earthquake source evolution that possibly involves supershear rupture in a geometrically complex fault system requires finite-fault inversion that is more flexible than conventional inversion schemes. Conventional inverse solutions have been stabilized by limiting the model space and decreasing the degree of freedom for slip vectors. However, these limitations are not necessarily physical requirements for representing source processes. Moreover, inappropriate assumptions about the fault geometry can increase modeling errors, produce non-unique final solutions, and make it difficult to interpret those solutions (Shimizu et al., 2020, Text S1). By introducing the uncertainty of the Green's function into the data covariance matrix (Yagi and Fukahata, 2011, Duputel et al., 2014, Minson et al., 2013, Ragon et al., 2018), we were able to represent slip evolution without applying unnecessary solution-stabilizing constraints (e.g., non-negative slip). However still, confining a fault geometry a priori remains an inherent limitation that possibly violates the inversion solution (Shimizu et al., 2020).

Complexity or spatial variations of fault geometry in a finite-fault inversion can be accounted for by representing fault deformation by fault-normal and shear-slip vectors (potency-density tensors as defined by Ampuero and Dahlen (2005)) with the five basis double-couple components (Kikuchi and Kanamori, 1991). This extension of conventional source inversion makes it possible to freely represent fault-normal and shear-slip vectors on individual subfaults, whereby the fault plane spanned by slip vectors was no longer required to be identical to an arbitrarily chosen model plane geometry, thus suppressing modeling errors due to inappropriate assumptions about fault geometry (Shimizu et al., 2020). As shown by our sensitivity tests (Figs. S2 and S3), a complex fault geometry represented by a mixture of focal mechanisms was well resolved by our inversion. For convenience, we refer here to the scalar potency density resolved by our inversion as slip. Although the units of measure for scalar potency density and slip are the same, the inverted slip we determined was underestimated because, in our inversion, we adopted a planar fault model that was not necessarily identical to the true fault, and the area of each source element 
(subfault) of the model fault became small if the model fault deviated from the true fault. Also note that the amount of slip resolved can be underestimated owing to the smoothing constraint adopted in the inversion (Fig. S2)

Modeling of possible supershear rupture requires a vast model space to capture the high-speed rupture front and the following slip, which may endure after passage of the rupture front. In our inversion scheme, we presumed a maximum rupture speed of $5.0 \mathrm{~km} / \mathrm{s}$, which exceeded the local shear-wave velocity (Table S1), by considering the possibility of supershear rupture during the 2018 Palu earthquake on the basis of the SEBP estimates of Bao et al. (2019). To ensure capture of supershear rupture and the following slip within the wide model space, we allowed slip durations of $15 \mathrm{~s}$ at each subfault. We tested the sensitivity and robustness of our modeling for different configurations of rupture speed and slip duration (see Figs. $\mathrm{S} 5-\mathrm{S} 7)$.

Then, we constructed a kinematic slip model by using the vertical component of 47 globally observed teleseismic $P$ waveforms (Fig. S1). In our inversion formulation, we used five basis double-couple components of the potency-density tensor (Ampuero and Dahlen, 2005) to represent slip (Shimizu et al., 2020), where a priori assumptions of fault geometry for each subfault in the model space are not required; instead, fault geometry is resolved by our inversion. That is, we simultaneously resolved both the spatiotemporal evolution of slip and the fault geometry of the 2018 Palu earthquake. The initial rupture point (hypocenter) was set at $0.256^{\circ} \mathrm{S}, 119.846^{\circ} \mathrm{E}$, and a depth of $12.0 \mathrm{~km}$, based on the origin location determined by USGS NEIC. We defined the model fault plane as a $240 \mathrm{~km}$ long $\times 30 \mathrm{~km}$ wide rectangle (strike $358^{\circ}$, dip $69^{\circ}$; based on the GCMT solution) discretized into evenly spaced $5 \mathrm{~km} \times 5$ $\mathrm{km}$ source elements, covering the potential source region resolved by InSAR analyses (Bao et al., 2019, Socquet et al., 2019).

\section{Results}

We identified two areas of large slip on the fault: $4.25 \mathrm{~m}$ of slip near the epicenter and $4.0 \mathrm{~m}$ of slip 60 $\mathrm{km}$ to the south (Figs. 2b and 3). The area of major slip (>50\% of maximum slip) was at depths shallower than $20 \mathrm{~km}$. The resultant release of seismic moment was $0.34 \times 10^{21} \mathrm{Nm}\left(M_{\mathrm{W}} 7.6\right)$, which is close to the GCMT solution of $0.28 \times 10^{21} \mathrm{Nm}\left(M_{\mathrm{W}} 7.6\right)$. The rupture front propagated mainly southward from the epicenter (Fig. 4). Areas of high slip-rate on the fault plane (closed contours defining roughly circular areas in Fig. 4 that look like eyeballs), which we refer to as "slipping patches" hereafter, were obtained near the epicenter and 60, 100, and $135 \mathrm{~km}$ south of the epicenter. The locus of maximum slip-rate on the fault plane within 1-s time windows, which we call the "slip-rate ridge" (Fig. 4), indicates how the slipping patches is distributed (isolated) in a certain region and time. For example, from 0 to $11 \mathrm{~s}$ after rupture initiation, the position along strike of the slip-rate ridge did not change, but remained close to the epicenter. From 11 to $14 \mathrm{~s}$, the slip-rate ridge moved southward, indicating the southward advance of the slipping patch. Delays and advances of the slipping patch are clearly evident in snapshots of the slip-rate distribution in strike-dip view, taken at $1 \mathrm{~s}$ intervals from rupture initiation (Fig. 5 and Movie 


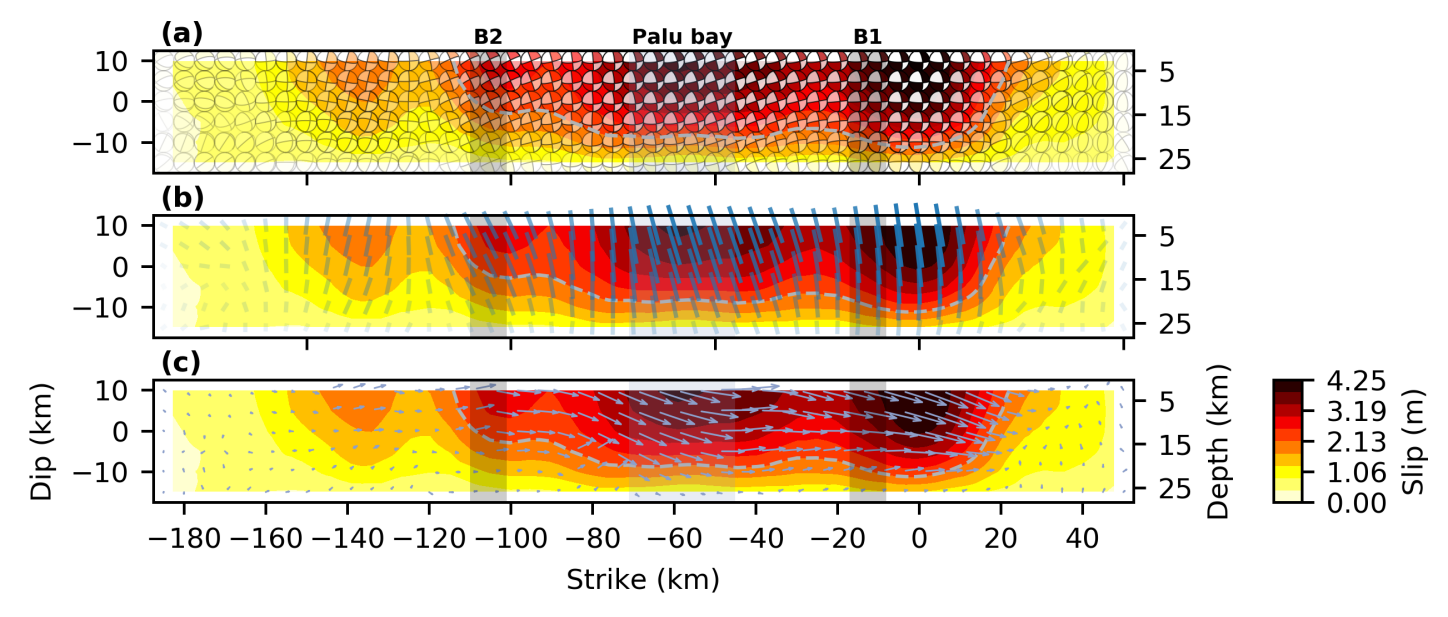

Figure 3: Static slip distribution in strike vs dip view. Background color represents the slip amplitude. Color-shaded areas are the bends and Palu Bay shown in Fig. 2. (a) The beachball shows a double-couple components of the potency-density tensor, plotted by using a lower-hemisphere stereographic projection, which are not rotated according to the model-plane geometry (not a view from side but from above). The distribution of (b) strike and (c) rake angles, which is extracted from the double-couple components of the resultant potency-density tensor. Length of line and arrow is scaled with slip.

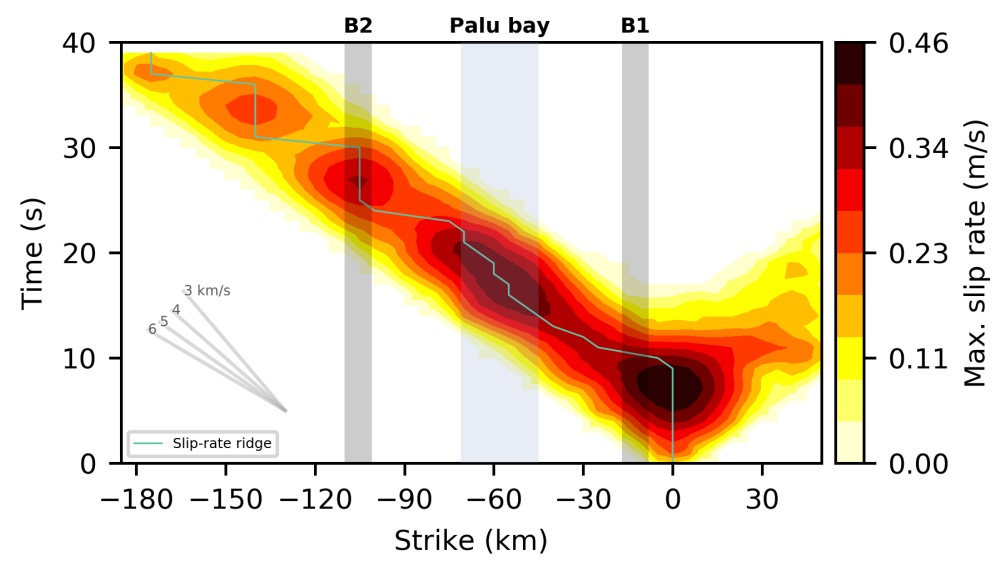

Figure 4: Temporal evolution of slip rate, projected along the model-plane strike $\left(358^{\circ}\right)$. The background color represents maximum slip-rate along dip of the model fault. The abscissa is a distance from the hypocenter, and the ordinate is a hypocentral time. The gray solid lines are the reference rupture speeds. Color-shaded areas are the bends and Palu Bay shown in Fig. 2. 
$\mathrm{S} 1)$. It is useful to consider three episodes of the rupture: from 8 to $17 \mathrm{~s}, 18$ to $27 \mathrm{~s}$, and 28 to $37 \mathrm{~s}$ after the initiation of rupture. In the first episode ( 8 to $17 \mathrm{~s})$, the slipping patch remained close to the epicenter from 8 to $11 \mathrm{~s}$, then moved suddenly southward from 11 to $14 \mathrm{~s}$ to a position $40 \mathrm{~km}$ south of the epicenter. In the second episode (18 to $27 \mathrm{~s}$ ), the slipping patch remained effectively stationary from 18 to $21 \mathrm{~s}$, then suddenly southward from 24 to $27 \mathrm{~s}$ to a position $105 \mathrm{~km}$ south of the epicenter. The third episode ( 28 to $37 \mathrm{~s}$ ) showed a similar pattern of an initial delay of the slipping patch followed by a sudden southward advance. This pattern of recurrent delay and advance of the fault slip was maintained when we changed the setting of maximum rupture velocity and slip duration (Fig. S7). Therefore, we consider them to be legitimate characteristics of the 2018 Palu earthquake.

The focal mechanism extracted from the modeled potency-density tensor showed some changes of strike orietnation on subfaults relative to that of the model fault plane. The static distribution of strike orientation on subfaults for one of the nodal planes extracted from the double-couple components of the resolved potency-density tensor solution (Figs. 2c and 3b) were obtained within $\pm 30^{\circ}$ of the strike of the model fault plane $\left(358^{\circ}\right)$. Deviations of the strike orientation of subfaults from that of the model fault plane were evident in the regions 30 to $70 \mathrm{~km}$ and 90 to $120 \mathrm{~km}$ south of the epicenter. Repeated rotations of the strike orientations of subfaults were also evident in snapshots of slip evolution (Figs. 5, 6 , and S11). When the slipping patch was near the epicenter, the strike angle was almost due north until about $10 \mathrm{~s}$ after rupture initiation, after which it changed to $330^{\circ}$ and moved to about $30 \mathrm{~km}$ south of the epicenter, where rapid southward migration of the slipping patch was evident in the snapshots from 11 to $14 \mathrm{~s}$ (Fig. 5). In snapshots from 17 to $21 \mathrm{~s}$, the slipping patch was 45 to $70 \mathrm{~km}$ south of the epicenter and remained relatively stationary with north-northwestward strike. Snapshots from 24 to $27 \mathrm{~s}$ show the slipping patch migrating rapidly to about $90 \mathrm{~km}$ south of the epicenter with roughly northward strike, but in the snapshot at $27 \mathrm{~s}$ the strike had rotated again the north-northwest and maintained that strike in the region from 100 to $120 \mathrm{~km}$ south of the epicenter in snapshots at 28 and $31 \mathrm{~s}$. Slip migration ceased about $160 \mathrm{~km}$ south of the epicenter with northerly strike as shown in snapshots at 34 and $37 \mathrm{~s}$. The repeated rotations of strike angle seemed to correspond to alternating episodes of stagnation and advance of the slipping patch.

\section{Discussion}

\subsection{Fault bends and supershear}

The trace of surface rupture mapped on the basis of InSAR analyses (Bao et al., 2019) shows two major bends in the Palu-Koro fault, one 10 to $25 \mathrm{~km}$ south of the epicenter (labeled B1 in Fig. 2) and another 100 to $110 \mathrm{~km}$ south of the epicenter (B2 in Fig. 2). Our finite-fault modeling showed overall persistence of supershear rupture propagation along the geometrically complex fault (Fig. 4). Dominant slipping patches were identified near the epicenter, beneath Palu Bay, and in the southern part of the fault system. The largest slip rates were modeled in the northern part of the source region from the epiecenter to Palu Bay region (Figs. 4 and 5). The World Stress Map (Heidbach et al., 2018) shows different orientations of the maximum horizontal stress for the northern and southern sections of the fault, 

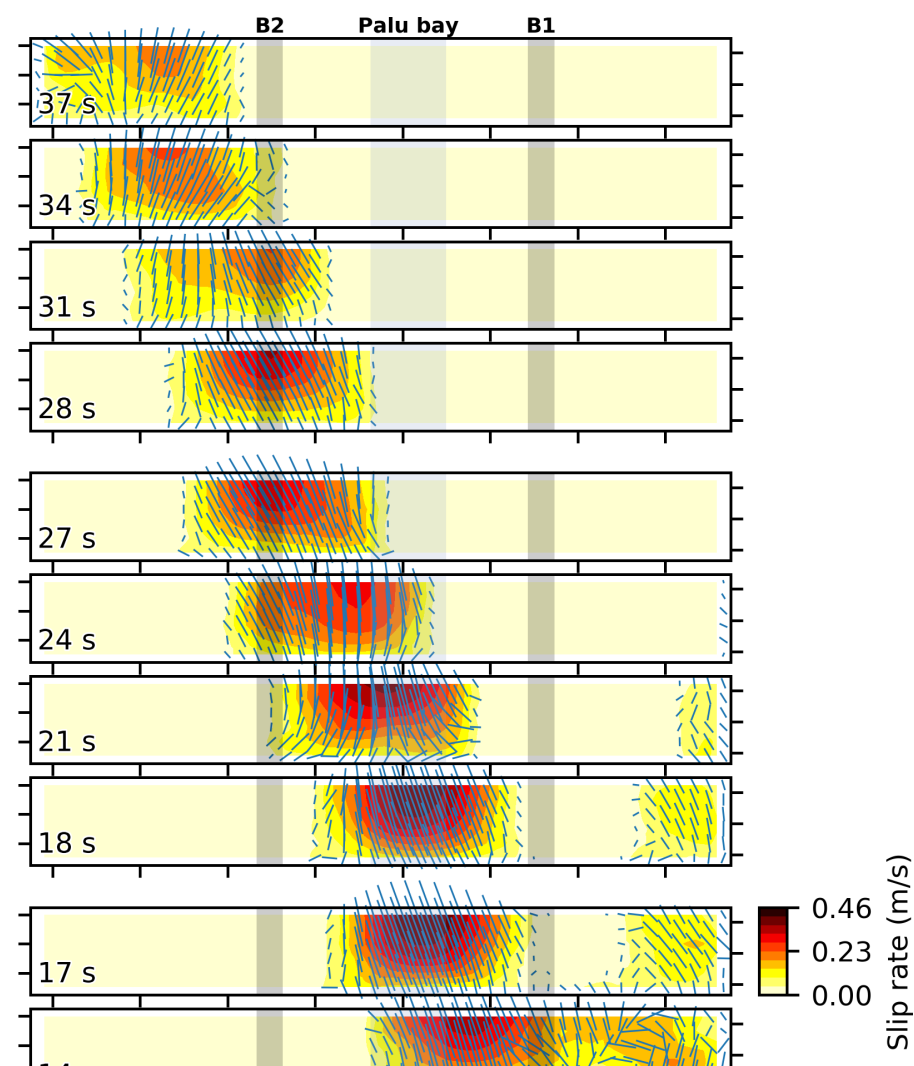

$14 \mathrm{~s}$
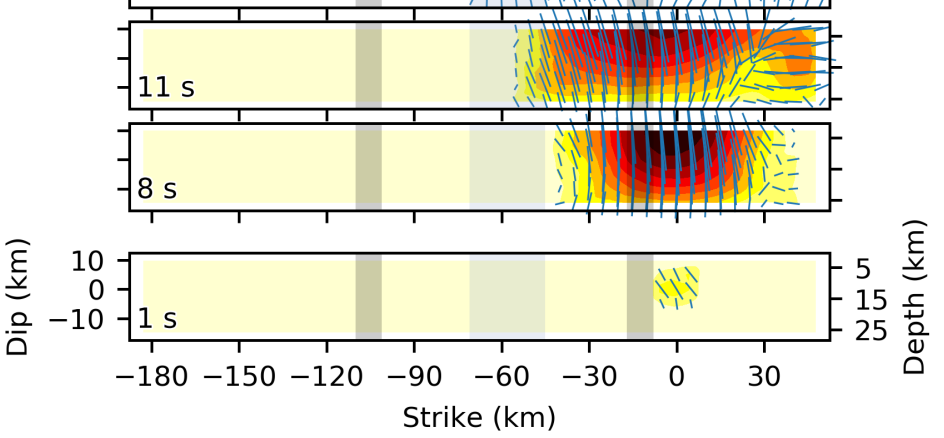

Figure 5: Snapshots of slip evolution. The background color represents slip rate. The blue line is a strike orientation. The hypocentral time at which the snapshot taken is denoted at left-bottom of each panel. Gray circles are the reference rupture speeds: 4, 5, and $6 \mathrm{~km} / \mathrm{s}$ expanding from the hypocenter. Color-shaded areas are the bends and Palu Bay shown in Fig. 2 . 

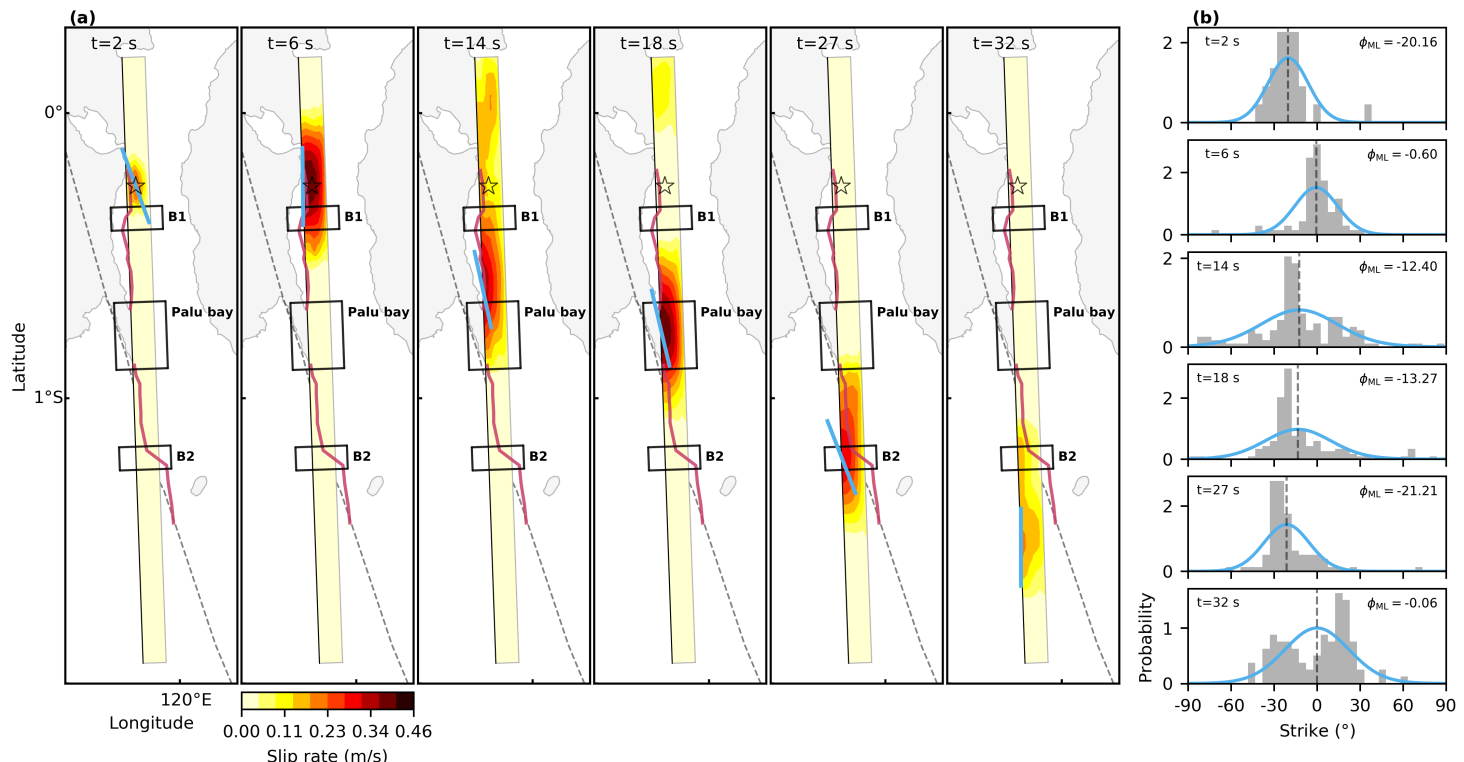

Figure 6: Selected snapshots of slip evolution and strike orientation. (a) Blue line is a maximum likelihood estimator ( $\left.\phi_{\mathrm{ML}}\right)$ of strike orientation for the von Mises distribution (Bishop, 2006), which are estimated from set of strike orientation along the model, where we resolved slip rate $>0 \mathrm{~m} / \mathrm{s}$. Center of blue line corresponds to the maximum slip-rate location for each snapshot. Dashed line is the Palu-Koro fault (Bellier et al., 2001). Red lines are the surface rupture traces mapped by the InSAR analyses (Bao et al., 2019). Black rectangles shows the location of bends and Palu Bay. Gray rectangle outlines a model-fault plane and the black line is a top of the model plane. The star denotes the epicenter. (b) Histogram of strike orientation every $2.5^{\circ}$ bin and its estimate of maximum likelihood. Blue curve is a probability density function for the maximum likelihood estimate of strike orientations using von Mises distribution with $\phi_{\mathrm{ML}}$. All the snapshots of distribution of strike orientation and its estimate of maximum likelihood are shown in Fig. S11. 
with the change occurring south of Palu Bay (Fig. S10). Given the known geometry of the Palu-Koro fault (Bellier et al., 2001) and the fault geometry we modeled, the northern part of the fault can be considered to represent the optimal plane for maximum mean horizontal stress, which likely explains the higher slip rates we modeled there. The optimal geometry of the northern part of the fault might also explain overall persistence of supershear rupture that started early on, given the proportional relationship between peak slip-rate and rupture speed, which in a supershear regime is enhanced relative to that in a sub-shear regime (Gabriel et al., 2013).

Besides the overall persistency of supershear rupture, which has been independently validated by SEBP and Mach cone analyses (Bao et al., 2019), our finite-fault model resolved transient periods of stagnation and advance of the migration of the slipping patches that appear to be associated with the geometric complexity of the fault. As discussed in Results section (see also Figs. 4 and 5), during the first $10 \mathrm{~s}$ after rupture initiation, a dominant slipping patch with a relatively high slip rate remained in proximity to the hypocenter; then, from 11 to $17 \mathrm{~s}$ after rupture initiation, the slipping patch advanced rapidly southward into Palu Bay region. If we compare the location of this slipping patch with the location of the InSAR-derived surface rupture trace, it appears that there was some hesitation before the slipping patch passed through the B1 bend (Figs. 4 and 6). Given that the 2018 Palu earthquake was caused by left-lateral strike-slip faulting, and that the strike of the primary fault plane is north to noth-northwest, it appears that the B1 fault bend was unfavorably oriented in relation to the optimal plane of the background stress field (Fig. S10). Bruhat et al. (2016) illuminated a case of supershear transition across a restraining fault bend in an area with a narrow range of background shear stress; the bend initially decelerated or arrested the rupture front, and the resultant concentration of local stress contributed to the subsequenct acceleration of the rupture front at supershear speed when it broke through the bend. Though our kinematic source model cannot uniquely determine the dominant physical factor that controlled the rupture process, dynamic changes of normal and shear stresses across the B1 bend may have induced both the delayed migration of the slipping patch from the vicinity of the hypocenter and its subsequent advance at supershear speed.

Another notable bend of the 2018 Palu earthquake fault system is the B2 bend (Fig. 2), which deviates eastward from the general trend of the southern part of the Palu-Koro fault. Although the exact stress condition is difficult to be inferred, the World Stress Map (Heidbach et al., 2018) shows the maximum horizontal stress is oriented at $115 \pm 11^{\circ}$ (Fig. S10). As demonstrated in the numerical simulation of the 2018 Palu earthquake of Ulrich et al. (2019), favorable conditions for rupture through the B2 bend require the maximum horizontal stress to be oriented east-west, which is close to the orientation according to the World Stress Map (Heidbach et al., 2018). The dominant slipping patch we modeled extended to the southern edge of Palu Bay ( $\sim 70 \mathrm{~km}$ south of the epicenter; Fig. 4$)$, but then migrated rapidly southward through the B2 bend with a relatively high slip rate from 24 to $27 \mathrm{~s}$ after rupture initiation. It appears that the B2 bend promoted the high slip rate within an area of relatively low background stress in the southern part of the fault (Fig. S10). Numerical simulations suggested that smooth or supershear propagation along the "releasing" bend can easily occur (Trugman and Dunham, 2014, Bruhat et al., 
2016). Therefore, the B2 bend can be a releasing bend to accelerate further slip evolution toward south involving high slip-rate within the bend.

Thus, our results provide evidence derived from observational data that geometric complexity of a fault has a role in accelerating and decelerating rupture propagation. Although it would be difficult to determine whether the accelerations and decelerations of rupture across fault bends was a result of rupture transitioning between sub-Rayleigh and supershear speeds, or perhaps a fluctuation of rupture evolution within the supershear regime, our results may provide input to further investigations of irregularities in rupture evolution associated with fault complexity in a supershear regime.

We note that there is a tradeoff between the locations of dominant slipping patches and the assumed maximum rupture velocity and maximum slip-rate duration for each subfault (Fig. S7); it is therefore difficult to derive a unique location of a dominant slipping patch solely from our slip models. On the basis of comparison of the locations of our dominant slipping patches with the InSAR-derived surface rupture trace, we propose that our model with a rupture velocity of $5 \mathrm{~km} / \mathrm{s}$ and a slip-rate duration of $15 \mathrm{~s}$ provides the optimal model for the 2018 Palu earthquake, which is why we have focused on that model in the Results and Discussion sections (Figs. 2 to 6). We also identified a slipping patch at the southern end of the model fault for which slip migration ceased about $40 \mathrm{~s}$ after rupture initiation (Fig. 4). However, detailed evaluation of slip in this area was difficult (Text S2) because a clear surface rupture trace based on InSAR data is not available in that area, and, because of the requirement to use a rectangular model fault plane, the model fault deviates from the Palu-Koro fault line in that area (Fig. 2).

\subsection{Possible fault junction beneath Palu Bay}

The surface rupture trace of the 2018 Palu earthquake, mapped in the northern part of the modeled region from InSAR data and reproduced by our inversion, trends approximately north, deviating from the established north-northwest trend of the Palu-Koro fault in this region (Fig. 2). South of Palu Bay, the surface rupture follows tne trend of the Palu-Koro fault (Bellier et al., 2001, 2006, Fig. 2), except in the area of the B2 fault bend. The change of strike between the northern and southern parts of the fault appears to be around Palu Bay. The northern part of the fault, where the 2018 rupture was initiated, had not been mapped prior to the 2018 earthquake, and if it is not part of the Palu-Koro fault system, the southward propagation rupture would need to cross a fault junction beneath Palu Bay. Although the likely fault junction is underwater and has not been identified from InSAR data, our inversion indicated that the strike of the dominant slipping patch beneath Palu Bay was north-northwest (Fig. 2c), which is consistent with that of the Palu-Koro fault. Moreover, the delayed migration of the slipping patch around Palu Bay (Fig. 4) suggests there may be a fault junction under the bay that prevents smooth slip evolution.

The relatively low spatial resolution of the teleseismic data we used in our inversion means that the fault goemetry we resolved may not agree exactly with the surface-rupture trace mapped from InSAR analyses (Bao et al., 2019, Text S2). Nonetheless, our model captured a change of strike of the fault as the rupture propagated across Palu Bay (Figs. 2 and 5).

Another notable feature identified by our inversion beneath Palu Bay is that the focal mechanism we de- 
termined there indicates normal dip-slip. We therefore suggest the dominant slipping patch beneath Palu Bay may have contributed to generation of the 2018 Palu tsunami, which is consistent with earthquaketsunami modeling by Ulrich et al. (2019).

\subsection{Inchworm-like slip evolution; How do we infer rupture behavior from inversion?}

In our inversion scheme, the relationship between slip migration and rupture-front propagation is nontrivial because we explicitly assumed a maximum rupture velocity; therefore, the rupture front (the edge of the model space where the following slip is represented) is arbitrarily defined by that velocity. We now consider a simple kinematic slip model (Fig. S9 and Text S4) in which we assume that a rupture pulse propagates at constant rupture-front velocity with oscillating slip velocity. This simple kinematic model, involving only the oscillation of slip velocity, can be realized if there is a heterogeneous distribution of breakdown stress drop, even if the rupture front propagates at a constant speed, given that maximum slip velocity is proportional to breakdown stress drop (Ida, 1972, Gabriel et al., 2012). The pattern of the slip-rate distribution obtained for this model (Fig. S9) looks similar to that we obtained in our inversion (Fig. 4). However, the slip-rate ridge in this simple kinematic model is a straight line, indicating that the location of the slipping patch is migrating at constant speed, even though the slip velocity is oscillating. In our slip model for the 2018 Palu earthquake (Fig. 4), the slip-rate ridge shows a zigzag pattern involving periods of stangancy and advancement of slip, which is not explained by the above simple kinematic model. In our inversion, we resolved changes of rupture velocity followed by peculiar repetitions of slip deceleration and acceleration associated with fault bends in the geometrically complex fault system; we called this inchworm-like slip evolution. The modeled migration speed of the slipping patch is well above the local $S$-wave velocity ( $>4 \mathrm{~km} / \mathrm{s}$; Figs. 4 and 5 ; Text $\mathrm{S} 3$ ), both when it advanced across the B1 fault bend and when it passed through the B2 fault bend after traversing the possible fault junction beneath Palu Bay. If we assume that the migration of the slipping patch follows the rupture front, our inversion result should represent supershear rupture evolution related to the geometric complexity of the fault system. Thus, we propose that the geometric complexity of a fault system can be a key factor in promoting persistent supershear rupture, which enhanced by recurrent inchworm-like slip evolution (Fig. 6 and Movie S1).

\section{Conclusion}

Our modeling of slip during the 2018 Palu earthquake showed a peculiar evolution of slip that manifested as repetitive periods of stagnation and advancement of slip that appeared to be associated with two fault bends and a possible fault junction beneath Palu Bay. We propose that the overall persistence of supershear rupture propagation during the 2018 Palu earthquake was a response to the geometric complexity of the fault system, which was the key driver of the transient and episodic acceleration and deceleration of slip evolution. 


\section{Acknowledgements}

We thank the editor and the reviewers for their handling and thorough review of this manuscript. This work was supported by Grants-in-Aid for Japan Society for the Promotion of Science (JSPS) Fellows (JP16J00298 and JP19J00814) and a Grant-in-Aid for Scientific Research (JP19K04030). The authors thank Han Bao and Jean-Paul Ampuero for providing the surface rupture trace and the results of their SEBP analyses of the 2018 Palu earthquake (Bao et al., 2019) and for their helpful comments on our work. Teleseismic waveforms were obtained from the following networks: the Australian National Seismograph Network (AU), GEOSCOPE (G; https://doi.org/10.18715/GEOSCOPE.G); the New China Digital Seismograph Network (IC; https://doi.org/10.7914/SN/IC); the Global Seismograph Network (GSN IRIS/IDA, II; https://doi.org/10.7914/SN/II), and the Global Seismograph Network (GSN IRIS/USGS, IU; https://doi.org/10.7914/SN/IU). All teleseismic waveform data were downloaded through the IRIS-DMC (https://ds.iris.edu/ds/nodes/dmc/). The topography and bathymetry used in Fig. 1 are from GEBCO 2019 Grid (GEBCO Bathymetric Compilation Group 2019, 2019, https://doi.org/10/c33m). The figures were generated with matplotlib (Hunter, 2007, Version v3.0.0; https://doi.org/10.5281/zenodo.1420605) and ObsPy (Beyreuther et al., 2010, Megies et al., 2011, Krischer et al., 2015, Version v1.1.0; https://doi.org/10.5281/zenodo.599698). All the data and results presented in this study are stored in a Github repository (https://github.com/rokuwaki).

\section{References}

Aki, K., 1979. Characterization of barriers on an earthquake fault, J. Geophys. Res., 84(B11), 6140, doi: 10.1029/JB084iB11p06140.

Ampuero, J.-P. and Dahlen, F. A., 2005. Ambiguity of the Moment Tensor, Bull. Seism. Soc. Am., 95(2), 390, doi: $10.1785 / 0120040103$

Bao, H., Ampuero, J.-P., Meng, L., Fielding, E. J., Liang, C., Milliner, C. W. D., Feng, T., and Huang, H., 2019. Early and persistent supershear rupture of the 2018 magnitude 7.5 Palu earthquake, Nat. Geosci., 12(3), 200-205, doi: $10.1038 / \mathrm{s} 41561-018-0297-\mathrm{z}$

Bellier, O., Sebrier, M., Beaudouin, T., Villeneuve, M., Braucher, R., Bourles, D., Siame, L., Putranto, E., and Pratomo, I., 2001. High slip rate for a low seismicity along the Palu-Koro active fault in central Sulawesi (Indonesia), Terra Nov., 13(6), 463-470, doi: 10.1046/j.1365-3121.2001.00382.x.

Bellier, O., Sébrier, M., Seward, D., Beaudouin, T., Villeneuve, M., and Putranto, E., 2006. Fission track and fault kinematics analyses for new insight into the Late Cenozoic tectonic regime changes in West-Central Sulawesi (Indonesia), Tectonophysics, 413(3-4), 201-220, doi: 10.1016/j.tecto.2005.10.036.

Beyreuther, M., Barsch, R., Krischer, L., Megies, T., Behr, Y., and Wassermann, J., 2010. ObsPy: A Python Toolbox for Seismology, Seismol. Res. Lett., 81(3), 530-533, doi: 10.1785/gssrl.81.3.530.

Bird, P., 2003. An updated digital model of plate boundaries, Geochemistry, Geophys. Geosystems, 4(3), 1105, doi: 10.1029/2001GC000252.

Bishop, C. M., 2006. Pattern Recognition and Machine Learning, Springer.

Bouchon, M., Bouin, M.-P., Karabulut, H., Toksöz, M. N., Dietrich, M., and Rosakis, A. J., 2001. How fast is rupture during an earthquake? New insights from the 1999 Turkey Earthquakes, Geophys. Res. Lett., 28(14), 2723-2726, doi: 10.1029/2001GL013112.

Bouchon, M., Karabulut, H., Bouin, M.-P., Schmittbuhl, J., Vallée, M., Archuleta, R., Das, S., Renard, F., and Marsan, D., 2010. Faulting characteristics of supershear earthquakes, Tectonophysics, 493(3-4), 244-253, doi: 10.1016/j.tecto.2010.06.011. 
Bruhat, L., Fang, Z., and Dunham, E. M., 2016. Rupture complexity and the supershear transition on rough faults, J. Geophys. Res. Solid Earth, 121(1), 210-224, doi: 10.1002/2015JB012512.

Das, S. and Aki, K., 1977. Fault plane with barriers: A versatile earthquake model, J. Geophys. Res., 82(36), 5658-5670, doi: $10.1029 / \mathrm{JB} 082 \mathrm{i036p05658.}$

Dunham, E. M. and Bhat, H. S., 2008. Attenuation of radiated ground motion and stresses from three-dimensional supershear ruptures, J. Geophys. Res. Solid Earth, 113(B8), 1-17, doi: 10.1029/2007JB005182.

Dunham, E. M., Favreau, P., and Carlson, J. M., 2003. A supershear transition mechanism for cracks, Science (80-. )., 299(5612), 1557-1559, doi: 10.1126/science.1080650.

Duputel, Z., Agram, P. S., Simons, M., Minson, S. E., and Beck, J. L., 2014. Accounting for prediction uncertainty when inferring subsurface fault slip, Geophys. J. Int., 197(1), 464-482, doi: 10.1093/gji/ggt517.

Dziewonski, A. M., Chou, T.-A., and Woodhouse, J. H., 1981. Determination of earthquake source parameters from waveform data for studies of global and regional seismicity, J. Geophys. Res. Solid Earth, 86(B4), 2825-2852, doi: 10.1029/JB086iB04p02825.

Ekström, G., Nettles, M., and Dziewoński, A., 2012. The global CMT project 2004-2010: Centroid-moment tensors for 13,017 earthquakes, Phys. Earth Planet. Inter., 200-201, 1-9, doi: 10.1016/j.pepi.2012.04.002.

Gabriel, A.-A., Ampuero, J.-P., Dalguer, L. A., and Mai, P. M., 2012. The transition of dynamic rupture styles in elastic media under velocity-weakening friction, J. Geophys. Res. Solid Earth, 117(B9), 1-20, doi: 10.1029/2012JB009468.

Gabriel, A.-A., Ampuero, J.-P., Dalguer, L. A., and Mai, P. M., 2013. Source properties of dynamic rupture pulses with off-fault plasticity, J. Geophys. Res. Solid Earth, 118(8), 4117-4126, doi: 10.1002/jgrb.50213.

GEBCO Bathymetric Compilation Group 2019, 2019. The GEBCO_2019 Grid - a continuous terrain model of the global oceans and land, doi: https://doi.org/10/c33m.

Hartzell, S. H. and Heaton, T. H., 1983. Inversion of strong ground motion and teleseismic waveform data for the fault rupture history of the 1979 Imperial Valley, California, earthquake, Bull. Seism. Soc. Am., 73(6A), 1553.

Heidbach, O., Rajabi, M., Cui, X., Fuchs, K., Müller, B., Reinecker, J., Reiter, K., Tingay, M., Wenzel, F., Xie, F., Ziegler, M. O., Zoback, M.-L., and Zoback, M., 2018. The World Stress Map database release 2016: Crustal stress pattern across scales, Tectonophysics, 744, 484-498, doi: 10.1016/j.tecto.2018.07.007.

Huang, Y., 2018. Earthquake Rupture in Fault Zones With Along-Strike Material Heterogeneity, J. Geophys. Res. Solid Earth, 123(11), 9884-9898, doi: 10.1029/2018JB016354.

Hunter, J. D., 2007. Matplotlib: A 2D Graphics Environment, Comput. Sci. Eng., 9(3), 90-95, doi: 10.1109/MCSE.2007.55.

Ida, Y., 1972. Cohesive force across the tip of a longitudinal-shear crack and Griffith's specific surface energy, J. Geophys. Res., 77(20), 3796-3805, doi: 10.1029/JB077i020p03796.

Kase, Y. and Day, S. M., 2006. Spontaneous rupture processes on a bending fault, Geophys. Res. Lett., 33(10), 1-4, doi: 10.1029/2006GL025870.

Kikuchi, M. and Kanamori, H., 1991. Inversion of complex body waves-III, Bull. Seism. Soc. Am., 81(6), 2335-2350.

Krischer, L., Megies, T., Barsch, R., Beyreuther, M., Lecocq, T., Caudron, C., and Wassermann, J., 2015. ObsPy: a bridge for seismology into the scientific Python ecosystem, Comput. Sci. Discov., 8(1), 014003, doi: 10.1088/17494699/8/1/014003.

Mai, P. M., Schorlemmer, D., Page, M., Ampuero, J., Asano, K., Causse, M., Custodio, S., Fan, W., Festa, G., Galis, M., Gallovic, F., Imperatori, W., Käser, M., Malytskyy, D., Okuwaki, R., Pollitz, F., Passone, L., Razafindrakoto, H. N. T., Sekiguchi, H., Song, S. G., Somala, S. N., Thingbaijam, K. K. S., Twardzik, C., van Driel, M., Vyas, J. C., Wang, R., Yagi, Y., and Zielke, O., 2016. The Earthquake-Source Inversion Validation (SIV) Project, Seismol. Res. Lett., 87(3), 690-708, doi: 10.1785/0220150231.

Megies, T., Beyreuther, M., Barsch, R., Krischer, L., and Wassermann, J., 2011. ObsPy - What can it do for data centers and observatories?, Ann. Geophys., 54(1), 47-58, doi: 10.4401/ag-4838.

Meng, L., Zhang, A., and Yagi, Y., 2016. Improving back projection imaging with a novel physics-based aftershock calibration approach: A case study of the 2015 Gorkha earthquake, Geophys. Res. Lett., 43(2), 628-636, doi: 10.1002/2015GL067034.

Minson, S. E., Simons, M., and Beck, J. L., 2013. Bayesian inversion for finite fault earthquake source models I-theory and algorithm, Geophys. J. Int., 194(3), 1701-1726, doi: 10.1093/gji/ggt180. 
Okuwaki, R. and Yagi, Y., 2018. Role of geometric barriers in irregular-rupture evolution during the 2008 Wenchuan earthquake, Geophys. J. Int., 212(3), 1657-1664, doi: 10.1093/gji/ggx502.

Olson, A. H. and Apsel, R. J., 1982. Finite faults and inverse theory with applications to the 1979 Imperial Valley earthquake, Bull. Seism. Soc. Am., 72(6A), 1969.

Oral, E., Weng, H., and Ampuero, J. P., 2020. Does a damaged-fault zone mitigate the near-field impact of supershear earthquakes?-Application to the 2018 M w 7.5 Palu, Indonesia earthquake, Geophys. Res. Lett., doi: 10.1029/2019GL085649.

Ragon, T., Sladen, A., and Simons, M., 2018. Accounting for uncertain fault geometry in earthquake source inversions - I: theory and simplified application, Geophys. J. Int., 214(2), 1174-1190, doi: 10.1093/gji/ggy187.

Shimizu, K., Yagi, Y., Okuwaki, R., and Fukahata, Y., 2020. Development of an inversion method to extract information on fault geometry from teleseismic data, Geophys. J. Int., 220(2), 1055-1065, doi: 10.1093/gji/ggz496.

Socquet, A., Simons, W., Vigny, C., McCaffrey, R., Subarya, C., Sarsito, D., Ambrosius, B., and Spakman, W., 2006. Microblock rotations and fault coupling in SE Asia triple junction (Sulawesi, Indonesia) from GPS and earthquake slip vector data, J. Geophys. Res., 111(B8), B08409, doi: 10.1029/2005JB003963.

Socquet, A., Hollingsworth, J., Pathier, E., and Bouchon, M., 2019. Evidence of supershear during the 2018 magnitude 7.5 Palu earthquake from space geodesy, Nat. Geosci., 12(3), 192-199, doi: 10.1038/s41561-018-0296-0.

Trugman, D. T. and Dunham, E. M., 2014. A 2D Pseudodynamic Rupture Model Generator for Earthquakes on Geometrically Complex Faults, Bull. Seismol. Soc. Am., 104(1), 95-112, doi: 10.1785/0120130138.

Uchide, T., Yao, H., and Shearer, P. M., 2013. Spatio-temporal distribution of fault slip and high-frequency radiation of the 2010 El Mayor-Cucapah, Mexico earthquake, J. Geophys. Res. Solid Earth, 118(4), 1546-1555, doi: 10.1002/jgrb.50144.

Ulrich, T., Vater, S., Madden, E. H., Behrens, J., van Dinther, Y., van Zelst, I., Fielding, E. J., Liang, C., and Gabriel, A., 2019. Coupled, Physics-Based Modeling Reveals Earthquake Displacements are Critical to the 2018 Palu, Sulawesi Tsunami, Pure Appl. Geophys., 176(10), 4069-4109, doi: 10.1007/s00024-019-02290-5.

Vallée, M. and Dunham, E. M., 2012. Observation of far-field Mach waves generated by the 2001 Kokoxili supershear earthquake, Geophys. Res. Lett., 39(5), 1-5, doi: 10.1029/2011GL050725.

Yagi, Y. and Fukahata, Y., 2011. Introduction of uncertainty of Green's function into waveform inversion for seismic source processes, Geophys. J. Int., 186(2), 711-720, doi: 10.1111/j.1365-246X.2011.05043.x. 